\title{
Physical Activity in the Prevention and Treatment of Stroke
}

\author{
Siobhan Gallanagh, ${ }^{1}$ Terry J. Quinn, ${ }^{2}$ Jen Alexander, ${ }^{3}$ and Matthew R. Walters ${ }^{2}$ \\ ${ }^{1}$ School of Medicine, University of Glasgow, Glasgow G12 8QQ, UK \\ ${ }^{2}$ Institute of Cardiovascular and Medical Sciences, University of Glasgow, Glasgow G11 6NT, UK \\ ${ }^{3}$ Department of Physiotherapy, Western Infirmary, Glasgow G11 6NT, UK \\ Correspondence should be addressed to Matthew R. Walters, matthew.walters@glasgow.ac.uk
}

Received 2 July 2011; Accepted 4 August 2011

Academic Editors: W. D. Byblow, A. Lagares, R. L. Macdonald, and Y. Shinohara

Copyright (๑) 2011 Siobhan Gallanagh et al. This is an open access article distributed under the Creative Commons Attribution License, which permits unrestricted use, distribution, and reproduction in any medium, provided the original work is properly cited.

\begin{abstract}
The role of physical activity in the prevention of stroke is of great interest due to the high mortality and significant impact of stroke-related morbidity on the individual and on healthcare resources. The use of physical activity as a therapeutic strategy to maximise functional recovery in the rehabilitation of stroke survivors has a growing evidence base. This narrative review examines the existing literature surrounding the use of exercise and physical therapy in the primary and secondary prevention of stroke. It explores the effect of gender, exercise intensities and the duration of observed benefit. It details the most recent evidence for physical activity in improving functional outcome in stroke patients. The review summaries the current guidelines and recommendations for exercise therapy and highlights areas in which further research and investigation would be useful to determine optimal exercise prescription for effective prevention and rehabilitation in stroke.
\end{abstract}

\section{Introduction}

Stroke is a leading cause of mortality and morbidity worldwide. In the UK stroke is the third most common cause of death and the main cause of acquired disability. Approximately 130,000 individuals experience a first ever stroke per annum [1]. In addition to widely applicable pharmacological treatment for acute stroke, effective prevention and rehabilitation strategies are crucial. The development of such strategies is a major challenge for the 21 st century medicine.

Exercise and physical activity have an increasing evidence base in the primary and secondary prevention of stroke and in stroke rehabilitation. The interface between physical activity and cerebrovascular disease is complex and of broad interest to clinicians, therapists, and epidemiologists. The importance of the relationship is becoming clearer: physical inactivity has been implicated by the INTERSTROKE study as one of the 5 key risk factors which account for more than $80 \%$ of the global burden of stroke [2]. Physical fitness training is increasingly being recommended as a component of stroke rehabilitation programmes due to the emerging body of evidence surrounding the benefits in improving the function after stroke [3]. The role of long-term physical activity in patients who have had a stroke in the prevention of further stroke is less clear. This paper provides a narrative review of the literature which addresses the interface between physical activity and cerebrovascular disease with specific reference to prevention of stroke and poststroke rehabilitation.

\section{Search Strategy}

A computer-assisted literature search was performed using the database Ovid MEDLINE (1950-June Week 4 2010) and the database EMBASE (1980 to 2010 Week 25). Briefly, we sought to identify studies examining the relationship between exercise or physical activity and cerebrovascular risk and studies examining the effect of exercise or physical activity in populations with cerebrovascular disease. Reference lists of all identified relevant articles and reviews were screened to identify other potentially eligible studies.

\section{Effect of Exercise on Modifiable Cardiovascular Risk Factors}

Hypertension is recognised as the most important modifiable risk factor for both ischaemic and haemorrhagic stroke [4]. 
A strong and well-recognised relationship exists between blood pressure and stroke risk [5]. Physical activity is associated with reductions in blood pressure and in the risk of developing hypertension in healthy normotensive individuals [6-8], thus positively altering a major contributor to stroke risk.

The mechanistic basis of the effect of exercise on stroke risk is likely to be multifactorial. Regular exercise is known to increase the activity of nitric oxide synthase improving endothelial function, reduce left ventricular hypertrophy; stimulate elevations in plasma tissue plasminogen activator and HDL concentrations, and reduce fibrinogen and platelet activity. Aerobic conditioning has been shown to enhance glucose regulation and promote reductions in total serum and LDL cholesterol, triglycerides, total body fat, and systemic inflammation (Figure 1) [9-15]. Therefore, among other mechanisms, exercise helps to prevent obesity, hypertension, dyslipidaemia, and the development of type 2 diabetes, all of which are implicated in the pathogenesis of stroke.

\section{Physical Activity in Primary Prevention of Stroke}

Exercise and physical activity have a well-established evidence base for their benefits in reducing cardiovascular risk factors through the mechanisms described above. Observational studies have found an inverse association between physical activity and stroke risk [16-30], with recent reviews estimating that physical activity is associated with a $25-30 \%$ risk reduction for stroke [31], however, this finding has not been consistently reproduced in the literature, with other groups reporting U-shaped associations or no associations at all [32-37] (Table 1).

Differences in methodology, patient populations, and exercise interventions are likely to have contributed to this disparity. Studies generally, have been limited by their observational design and variations in adjustment for residual confounding. Some of the studies are retrospective and case control, which may have introduced selection and recall bias. Many of the studies use subjective measures to quantify the frequency and intensity of exercise, incorporating reporting bias. The lack of standard definitions of exercise intensity and the wide variability of exercise undertaken by participants into these studies introduce significant complexity to the meta-analysis and the clouds interpretation of the results. Populations studied differ in terms of ethnicity, age, and gender. In some prospective studies which have examined the effect of exercise on various cardiovascular endpoints [38], an inverse relationship between physical activity and risk of coronary heart disease has been demonstrated; however, the relationship between exercise and stroke risk has been less substantiated. It is likely that this is, in part, due to the lower incidence of cerebrovascular events over the study period. Finally, the majority of the studies did not apply repeated measures of physical activity, and many were underpowered to detect significant associations.

A meta-analysis by Lee et al. included 18 cohort and 5 case control studies and concluded that moderately and high physically active individuals have lower stroke incidence and mortality. The relative reduction in stroke incidence observed in moderately and highly active individuals was estimated at between 20 and $27 \%$ [39].

Further evidence in support of a beneficial effect of exercise on stroke risk can be found in a meta-analysis of observational data from cohort and case control studies which investigated the effects of occupational and leisuretime physical activity on the risk of stroke [40]. The findings of the meta-analysis were that a high level of occupational physical activity was associated with a stroke risk reduction of $43 \%$ when compared to occupational inactivity and a relative stroke risk reduction of $23 \%$ when compared to a moderate level of occupational activity. Moderate amounts of physical activity at work were associated with a $36 \%$ reduction in risk of stroke compared with being inactive at work. High levels of leisure-time physical activity were associated with a stroke risk reduction of $20-25 \%$ when compared to being inactive during leisure time. The risk reduction when comparing moderate levels of leisure-time physical activity to inactivity was $15 \%$.

Findings from further studies have been broadly supportive of the evidence that physical activity has an independent protective effect on the risk of cerebrovascular events [4146]. However, it appears that, within the topic of exercise in the primary prevention of stroke, there are issues which remain unresolved: the possibility of a gender-dependent difference in risk reduction, dubiety surrounding the intensities of exercise which are most beneficial, and lack of knowledge of the duration of the cerebrovascular benefits of exercise.

4.1. The Effect of Gender. A meta-analysis, including data from 33 prospective cohort studies and 10 case control studies addressing the effects of physical activity on strokerelated morbidity and mortality, found that the risk of an ischaemic stroke was reduced by $24 \%$ in women and $27 \%$ in men. However, they reported the effect to be statistically significant only for men [41]. This finding was supported by a further prospective study [46] but has not been reproduced in several large studies assessing the effect of exercise in females which have suggested benefit $[43,44]$.

A prospective cohort study of participants in the Women's Health Study [47] investigated the effect of different lifestyle components on stroke risk in women, found a weak association between risk of stroke and physical activity alone but combining physical activity with smoking cessation, low BMI, healthy diet and moderate alcohol consumption was associated with a significant reduction in stroke risk [43].

More recently, Sattelmair et al. investigated the effect of physical activity on stroke risk in 39315 women from the Women's Health Study (WHS) with a mean followup of 11.9 years [44]. They observed inverse associations of borderline significance between leisure-time physical activity and risk of stroke, with a $17 \%$ stroke risk reduction being observed for the most active women in comparison to the least active women in the study. In their report, they compared their results to those of a Japanese cohort [45], where a risk reduction of $17 \%$ (for fatal stroke only) was also observed, and to studies in Finland [29], Norway [18], and the United 


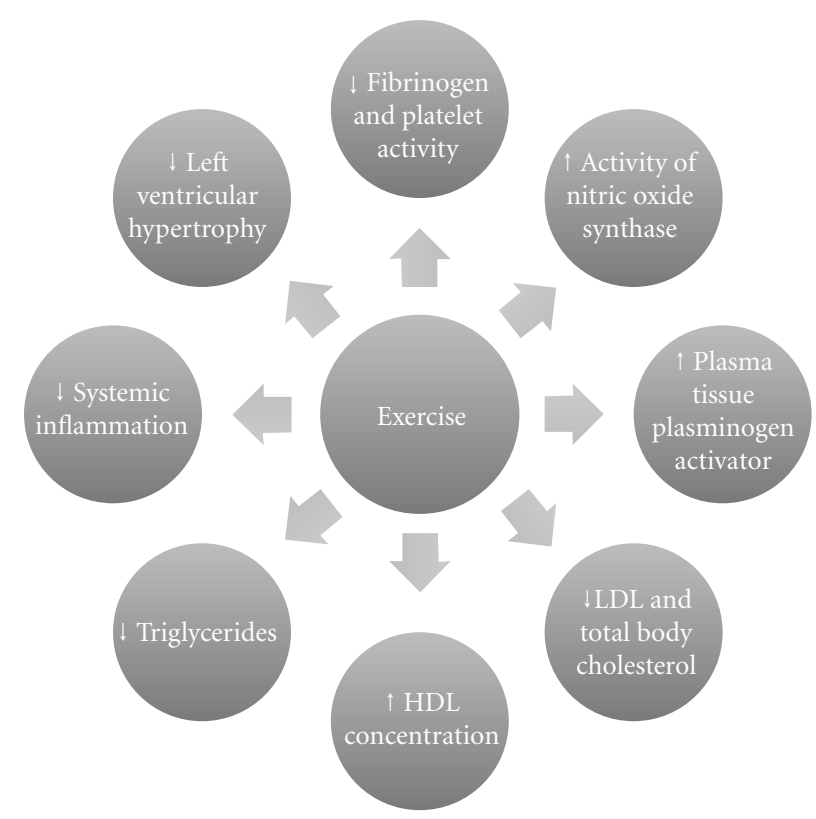

Figure 1: Putative pathophysiological benefits of exercise [9-15].

States [20] where risk reductions of 34\%, 53\% (for fatal stroke only), and $25 \%$, respectively, were reported.

Many of the studies have not included women; therefore, there is less evidence on exercise in the prevention of stroke for women from which to draw conclusions and formulate guidelines and recommendations.

4.2. Intensity of Exercise. The Northern Manhattan Stroke Study [25], a retrospective case control study that found leisure-time physical activity to be protective against ischaemic stroke, was followed recently by a prospective study in the same community [46]. The findings were that engaging in moderate to high intensities of physical activity, such as jogging, swimming, or tennis, was associated with a lower risk of ischaemic stroke; however, light activity (such as walking) did not confer the same benefit. The protective effect was seen only in men. This is in contrast to the findings of the Women's Health Initiative [47] and the Nurses' Health Study [20], where mild intensity physical activity, such as walking, was associated with a reduced risk of stroke.

4.3. Duration of Effect. In order to maintain the cardiovascular benefits and stroke risk reduction associated with exercising, patients must continue to participate in regular physical activity. If indeed a large proportion of the benefit of exercise on stroke risk reduction is mediated through its effect on reducing blood pressure, as some have suggested, then it is important to note that the positive effect of blood pressure reduction is reversible with cessation of exercise [48]. A recent case control study found no evidence of a protective effect of sporting activity during young adulthood against stroke and TIA in later life [49].

Evidence suggests that regular physical activity reduces the incidence and the mortality associated with stroke. The relative risk reduction appears to be somewhere between
20 and 30\%. Some studies, though not all, report a trend for higher risk reduction with higher intensity physical activity $[25,30,32,39,46]$. However, a recurring problem is that definitions of low, moderate, and high intensity physical activity vary widely between studies, and many of the trials have used self-reported physical activity questionnaires to assess levels of physical activity, which tend to be imprecise and biased with large measurement error. It is also clear that the degree of control over confounding variables has also varied among studies accounting for differences in values of risk reduction. Some trials have failed to demonstrate a significant reduction in stroke risk in women despite evidence of benefits in men. Possible reasons for this include smaller numbers of women being included in trials; therefore, studies are often underpowered to detect a significant effect, or confounders, which remain unaccounted for such as differences in diet or hormonal therapies, could be responsible for masking associations between physical activity and stroke risk in women.

In summary, published evidence favours an association between exercise and cardiovascular health. Beneficial effects of exercise on cerebrovascular risk reduction seem likely; however, definitive controlled trials are justified to establish the intensity and the frequency of exercise required to achieve benefits.

\section{Physical Activity in Prevention of Recurrent Stroke}

Approximately $30 \%$ of strokes are recurrent in nature [50]. Stroke and acute cardiac events have a higher incidence in patients with previous stroke than in the general population [51]. The American Heart Association's 2004 recommendations for Physical Activity in Stroke Survivors encourages targeting modifiable risk factors, such as physical 
TABLE 1: Characteristics of studies investigating physical activity and stroke risk.

\begin{tabular}{|c|c|c|c|c|c|c|c|}
\hline Study & Year & Methodology & $\begin{array}{l}\text { Number of } \\
\text { participants }\end{array}$ & Population Characteristics & $\begin{array}{l}\text { Followup } \\
\text { (years) }\end{array}$ & $\begin{array}{l}\text { Number } \\
\text { of stroke } \\
\text { events }\end{array}$ & $\begin{array}{l}\text { Relationship } \\
\text { between physical } \\
\text { activity and stroke }\end{array}$ \\
\hline Abott et al. [16] & 1994 & $\begin{array}{l}\text { Prospective } \\
\text { cohort }\end{array}$ & 7530 & $\begin{array}{l}\text { Male (Honolulu Heart Program) } \\
\text { 55-68 years }\end{array}$ & 22 & 537 & Inverse association \\
\hline Agnarsson et al. [17] & 1999 & $\begin{array}{l}\text { Prospective } \\
\text { cohort }\end{array}$ & 4484 & $\begin{array}{l}\text { Male (The Reykjavik Study) } 45-80 \\
\text { years }\end{array}$ & 10.6 & 249 & Inverse association \\
\hline Ellekjær et al. [18] & 2000 & $\begin{array}{l}\text { Prospective } \\
\text { cohort }\end{array}$ & 14101 & $\begin{array}{l}\text { Female (Nord-Trondelag Health } \\
\text { Survery) } \geq 50 \text { years }\end{array}$ & 10 & $\begin{array}{l}457 \\
\text { stroke } \\
\text { deaths }\end{array}$ & Inverse association \\
\hline Evenson et al. [19] & 1999 & $\begin{array}{l}\text { Prospective } \\
\text { cohort }\end{array}$ & 14575 & $\begin{array}{l}\text { Male and Female (The } \\
\text { Atherosclerosis Risk in Communities } \\
\text { Study) 45-64 years }\end{array}$ & 7.2 & 189 & Inverse association \\
\hline Hu et al. [20] & 2000 & $\begin{array}{l}\text { Prospective } \\
\text { cohort }\end{array}$ & 72488 & $\begin{array}{l}\text { Female (The Nurses' Health Study) } \\
40-65 \text { years }\end{array}$ & 8 & 407 & Inverse association \\
\hline Kiely et al. [21] & 1994 & $\begin{array}{l}\text { Prospective } \\
\text { cohort }\end{array}$ & 4196 & $\begin{array}{l}\text { Male and female (The Framingham } \\
\text { Study) 28-62 years }\end{array}$ & 32 & 427 & Inverse association \\
\hline Gillum et al. [22] & 1996 & $\begin{array}{l}\text { Prospective } \\
\text { cohort }\end{array}$ & 7895 & $\begin{array}{l}\text { Male and female (National Health } \\
\text { and Nutrition Examination Survey } \\
\text { I) } 45-74 \text { years }\end{array}$ & 11.6 & 623 & Inverse association \\
\hline Haheim et al. [23] & 1993 & $\begin{array}{l}\text { Prospective } \\
\text { cohort }\end{array}$ & 14403 & Male (Oslo Study) 40-49 years & 12 & 81 & Inverse association \\
\hline $\begin{array}{l}\text { Wannamethee and } \\
\text { Shaper [24] }\end{array}$ & 1992 & $\begin{array}{l}\text { Prospective } \\
\text { cohort }\end{array}$ & 7735 & $\begin{array}{l}\text { Male (British Regional Heart Study) } \\
40-59 \text { years }\end{array}$ & 9.5 & 128 & Inverse association \\
\hline Sacco et al. [25] & 1998 & $\begin{array}{l}\text { Retrospective } \\
\text { case control }\end{array}$ & $\begin{array}{l}369+678 \\
\text { controls }\end{array}$ & $\begin{array}{l}\text { Male and Female } \geq 39 \text { years } \\
1 \text { st ever cerebral infarction }\end{array}$ & - & - & Inverse association \\
\hline Shinton and Sagar [26] & 1993 & $\begin{array}{l}\text { Retrospective } \\
\text { case control }\end{array}$ & $\begin{array}{l}65+169 \\
\text { controls }\end{array}$ & $\begin{array}{l}\text { Male and female } 35-74 \text { years } \\
1 \text { st ever stroke and no significant } \\
\text { comorbidities }\end{array}$ & - & - & Inverse association \\
\hline You et al. [27] & 1995 & $\begin{array}{l}\text { Retrospective } \\
\text { case control }\end{array}$ & $\begin{array}{l}203+203 \\
\text { controls }\end{array}$ & $\begin{array}{l}\text { Male and female } 20-85 \text { years } \\
\text { Lacunar infarct }\end{array}$ & - & - & Inverse association \\
\hline You et al. [28] & 1997 & $\begin{array}{l}\text { Retrospective } \\
\text { case control }\end{array}$ & $\begin{array}{l}201+201 \\
\text { controls }\end{array}$ & $\begin{array}{l}\text { Male and female } 15-55 \text { years } \\
\text { Cerebral infarct }\end{array}$ & - & - & Inverse association \\
\hline Hu et al. [29] & 2005 & $\begin{array}{l}\text { Prospective } \\
\text { cohort }\end{array}$ & 47721 & Male and female 25-64 years & 19 & 2863 & Inverse association \\
\hline Williams et al. [30] & 2009 & $\begin{array}{l}\text { Prospective } \\
\text { cohort }\end{array}$ & 41402 & $\begin{array}{l}\text { Male and female (National Runners' } \\
\text { Health Study) }\end{array}$ & 7.7 & 119 & Inverse association \\
\hline Lee et al. [32] & 1999 & $\begin{array}{l}\text { Prospective } \\
\text { cohort }\end{array}$ & 21823 & $\begin{array}{l}\text { Male (Physicians Health Study) } \\
40-84 \text { years }\end{array}$ & 11.1 & $\begin{array}{l}533 \\
\text { stroke } \\
\text { deaths }\end{array}$ & $\begin{array}{l}\text { No clear } \\
\text { association }\end{array}$ \\
\hline $\begin{array}{l}\text { Lee and Paffenbarger Jr. } \\
\text { [33] }\end{array}$ & 1998 & $\begin{array}{l}\text { Prospective } \\
\text { cohort }\end{array}$ & 11130 & $\begin{array}{l}\text { Male (The Harvard Alumni Health } \\
\text { Study) } 43-88 \text { years }\end{array}$ & 13 & $\begin{array}{l}378 \\
\text { stroke } \\
\text { deaths }\end{array}$ & $\begin{array}{l}\text { U-shaped } \\
\text { association }\end{array}$ \\
\hline Fossum et al. [34] & 2007 & $\begin{array}{l}\text { Prospective } \\
\text { cohort }\end{array}$ & 9193 & $\begin{array}{l}\text { Male and female Left ventricular } \\
\text { hypertrophy and hypertension } \\
\text { patients (Losartan intervention for } \\
\text { endpoint reduction in hypertension } \\
\text { (LIFE) study) 55-80 years }\end{array}$ & 4.8 & $\begin{array}{c}541 \\
\text { strokes }\end{array}$ & Inverse association \\
\hline Lindsted et al. [35] & 1991 & $\begin{array}{l}\text { Prospective } \\
\text { cohort }\end{array}$ & 9484 & $\begin{array}{l}\text { Male (The Seventh Day Adventist } \\
\text { Study) } \geq 30 \text { years }\end{array}$ & 26 & $\begin{array}{l}410 \\
\text { stroke } \\
\text { deaths }\end{array}$ & $\begin{array}{l}\text { No inverse } \\
\text { association }\end{array}$ \\
\hline $\begin{array}{l}\text { Menotti and Seccareccia } \\
\text { [36] }\end{array}$ & 1985 & $\begin{array}{l}\text { Prospective } \\
\text { cohort }\end{array}$ & 99029 & $\begin{array}{l}\text { Male (Italian Railroad Workers } \\
\text { Study) } 40-59 \text { years }\end{array}$ & 5 & 187 & $\begin{array}{l}\text { No clear } \\
\text { association }\end{array}$ \\
\hline Simonsick et al. [37] & 1993 & $\begin{array}{l}\text { Prospective } \\
\text { cohort }\end{array}$ & 4840 & $\begin{array}{l}\text { Male and female (Established } \\
\text { Populations for Epidemiologic } \\
\text { Studies of the Elderly) } \geq 65 \text { years }\end{array}$ & 6 & - & $\begin{array}{l}\text { Inconsistent } \\
\text { relationships } \\
\text { between physical } \\
\text { activity and stroke }\end{array}$ \\
\hline
\end{tabular}

Key: — = Data not available. 
inactivity, to decrease the frequency of recurrent events. At present there is very limited long-term followup available examining physical activity levels and recurrent events in stroke survivors. Extrapolation of the effects of physical activity on cardiovascular risk factor reduction and physical fitness in the nonstroke population predicts that regular exercise delivered through stroke rehabilitation programmes may reduce the risk of further cerebrovascular and cardiovascular events in stroke survivors, subsequently reducing the risk of mortality in this population. A preliminary study, examining the effects of three different exercise interventions on cardiorespiratory fitness and coronary risk reduction in stroke survivors, found that 30 minutes of moderateintensity aerobic exercise was more effective than 60 minutes of lower-intensity aerobic exercise or nonaerobic therapeutic exercise in reducing blood pressure and blood lipid levels [52]. There is a general consensus that a potential stroke risk reduction may exist for stroke survivors who participate in regular physical activity; however, this is based largely upon the effect of exercise upon surrogate markers of stroke risk, and prospective clinical endpoint studies are lacking.

\section{Effect of Physical Activity on Functional Outcome after Stroke}

With recent improvements in the care of patients presenting with an acute stroke and wider availability of pharmacological treatments, the majority of patients are surviving the initial insult [53]. Despite this, only 1 in 3 patients with stroke makes a full recovery, and significant healthcare resource is consumed in the care of patients with stroke [54]. The evidence base for rehabilitation strategies after stroke is relatively weaker than acute treatments [55], and further work is needed to optimise rehabilitation, minimise impairment, and improve function in stroke survivors.

Physical fitness is greatly reduced in people after stroke when compared to their age-matched counterparts [56], and stroke sufferers with residual disability are less likely to exercise regularly $[57,58]$. This is predictable as many stroke survivors are left with residual impairments such as reduced mobility, poor balance, and decreased muscle strength making physical activity more challenging and a sedentary lifestyle more likely. Clinical guidelines for the management of stroke recommend physical activity as part of the rehabilitation process $[1,3]$ as evidence suggests that it can improve physical fitness and reduce the impact of strokeinduced disability [59]. Reducing disability can improve independence and overall quality of life [60].

The American Heart Association's scientific statement from 2004 concluded that training-induced cardiovascular health and fitness benefits seen in the general population may be extrapolated to stroke survivors [3]. This was based on evidence from five separate studies which collectively demonstrated improvements in peak oxygen consumption, submaximal energy expenditure, resting heart rate, peak left ventricular ejection fraction, aerobic capacity, and overall exercise capacity in stroke survivors undertaking aerobic exercise training [61-65]. This is consistent with data from studies involving both stroke and nonstroke patients, where benefits of regular physical activity in reducing multiple cardiovascular risk factors have been highlighted $[6,25,66-$ $68]$.

A meta-analysis assessing the effect of aerobic training on aerobic capacity by reviewing results from nine articles (seven randomised controlled trials) found that aerobic training achieving $50-80 \%$ of heart rate reserve, for 20 40 minutes, 3-5 days per week results in improved aerobic capacity as determined by peak oxygen consumption and peak workload. Most of the studies involved in the metaanalysis used the treadmill, cycle ergometer, or functional activities such as brisk stepping as a mode of aerobic training, and the analysis did not find that combining aerobic with resistance training resulted in improvements in aerobic capacity in this poststroke population [69].

Current stroke rehabilitation guidelines $[1,3]$ are generally centred around physiotherapy and occupational therapy regimens and are often focused on decreasing disability from stroke-induced impairment, to encourage patient independence as much as possible. The extent these programmes improve aerobic fitness is unclear, and experimental data have been inconsistent. One study found that rehabilitation programmes induced target heart rates in stroke patients suggesting the possibility of a training effect from functional exercise programmes [70]. However, another study evaluating the cardiovascular stress generated by physiotherapy and occupational therapy interventions in twenty patients enrolled in a stroke rehabilitation programme found that patients participating did not spend a large enough proportion of each session in their target heart rate zone and, therefore, were failing to generate an adequate cardiovascular stress to produce a training effect [71]. In addition, it is recognised that stroke rehabilitation programmes vary considerably between different centres, and; therefore, higher heart rates and prolonged durations of exertional tachycardia may occur with some programmes and not with others.

The loss or reduction in motor function is the most common and widely recognized impairment resulting from stroke [53]. Many studies investigating the benefits of exercise in stroke survivors have evaluated the benefit of physical therapy in improving function: strength, gait, and balance.

Previous advice to avoid strength training in stroke patients in order to decrease the chance of developing spasticity has not been substantiated [55]. On the contrary, the evidence for resistance training to improve muscle strength is abundant [64, 72-76] with a meta-analysis reporting a dose response relationship [77].

A recent meta-analysis by Langhorne et al. reported on a wide range of interventions that have been shown to improve motor function after stroke [53]. Upper limb functioning has been shown to improve significantly with the use of the following techniques: constraint-induced movement therapy (CIMT) [78], a form of physiotherapy where repetitive tasks are performed with the paretic limb, EMG biofeedback [79, 80] where electrodes are applied to the muscles to report electrical potentials to the patient via an auditory or visual means, mental imagery $[81,82]$ where physical functions are repeatedly mentally rehearsed, and robotics [83-85] which 
allow high-intensity repetitive movements of the upper limb to be carried out. A borderline effect was also observed in upper limb functioning with repetitive task training and electrostimulation [2] and bilateral movement training to improve control, and movement of the paretic limb has also shown favourable results in a meta-analysis [86].

The Copenhagen Stroke Study reported that 22\% of stroke survivors are unable to walk at the end of rehabilitation programmes [87]. Independent gait is closely related to independence and achievement of activities of daily living and, therefore, is one of the aims of physical training after stroke. A systematic review investigating the effectiveness of lower-limb strengthening, cardiorespiratory or gait-oriented tasks in improving gait, gait-related activities, and healthrelated quality of life in stroke survivors evaluated 21 randomised controlled trials. The evidence generated supports the conclusion that gait-oriented training improves walking competency after stroke but has no significant effect on activities of daily living or health-related quality of life [88]. A previously mentioned review examined the effects of cardiorespiratory with strength training, high-intensity physiotherapy, and repetitive task training on gait and found that only cardiorespiratory training is supported by strong evidence of beneficial effects on walking ability [53].

There is limited evidence that the use of technological devices improve gait in stroke patients. The use of electromechanical gait training to improve walking after stroke was evaluated in a systematic review of seventeen randomised controlled trials. Results indicated that electromechanicalassisted gait training in combination with physiotherapy after stroke enhances patients' chances of achieving independent walking. No benefits were found to walking speed or endurance [89]. Treadmill training was not found to be efficacious in improving walking in patients after stroke [90]; however, in a subgroup analysis, a trend towards better outcomes was demonstrated in patients using treadmill training with body weight support.

Biofeedback [91-94], where the patient is given information about his/her position and weight distribution using a force platform, and repetitive task training $[95,96]$ are the most frequently used interventions for improving balance in stroke survivors. However, neither intervention is supported by robust evidence of its effectiveness [53].

Participation in regular physical activity can be beneficial to patients who have had a stroke. Aerobic training has been shown to enhance physical fitness and reduce cardiovascular risk factors in stroke patients who are generally less physically active than age-matched counterparts, and physical activity guidelines now recommend dedicating more time to aerobic activity as part of stroke rehabilitation programmes to optimise cardiovascular and cerebrovascular benefits and reduce the risk of recurrent events [3]. Various trials have investigated the use of exercise and physical activity to improve strength, gait, and balance in patients with stroke. There is strong evidence to support the use of resistance training to improve muscle strength, and gait-oriented and cardiorespiratory training have shown potential benefits in improving gait and walking ability. Difficulties arise in providing guidelines for exercise recommendation in patients with stroke, as an individual's ability to exercise will vary with stroke subtype, residual disability, age, and comorbidity. Further detail regarding types of exercise and the optimal intensities and frequencies at which they should be performed should be sought in order to utilise the potential benefits of exercise in stroke patients.

Despite the potential benefits, in reality the implementation of exercise for stroke patients is complex; there are often significant barriers to exercise prescription. Clearly the nature and severity of the neurological deficit will influence the range of activities deemed suitable for the patient. Further, previous studies have highlighted that, even in the optimal setting of an acute stroke unit, the time devoted to each individual's physical and occupational therapy is limited by economic constraints, such as limited resources and personnel. As stroke is predominantly a disease of the elderly, many patients have significant comorbidities which may make regular physical activity less feasible [97, 98]. A meta-analysis by Kwakkel et al. suggests that greater intensity and frequency of therapy improve outcomes [98]; however, observed differences were modest and perhaps not worth the associated expense. Low mood and reduced selfesteem in the poststroke period could perhaps also contribute to the decreased motivation of patient to participate in exercise, especially group exercise. Finally, although a dose response relationship may exist between outcome and exercise, adverse events such as musculoskeletal injuries or sudden cardiac death is a potential threat. Guidelines encourage a preexercise evaluation of stroke patients to assess whether participation in exercise is suitable; the benefits outweigh the risks [3].

Further trials are required to provide robust evidence to enable the design of exercise regimens, which can be implemented into stroke rehabilitation programmes to maximise functional outcomes in patients after stroke.

\section{Conclusion}

Exercise and physical activity are useful tools in the rehabilitation and the functional recovery of patients who have suffered a stroke. In addition, physical activity potentially provides protective benefits in the prevention of stroke, which may extend beyond the positive effects on traditional cardiovascular risk factors.

Based on the available evidence, the American Heart Association (AHA) recommends that stroke survivors should undertake: strength training to increase independence in activities of daily living, flexibility training to increase range of movement and prevent deformities, and training to enhance balance and coordination. The AHA advises that each of these exercise modalities should be carried out twice or three times per week with the view to improving functional outcome after stroke. Aerobic exercise of moderate intensity should be carried out on at least three days of the week for twenty to sixty minutes at a time, in order to increase physical activity capacity, improve walking and independence, and reduce the risk of cardiovascular disease [3]. This guidance is derived, at least in part from the extrapolation of data from other non-stroke populations. 
Limitations highlighted in previous studies which have investigated the benefits of exercise in the prevention of stroke inhibit definitive conclusions regarding the type, frequency, and intensity of exercise that is required to confer a protective effect. Although some trials have included data on haemorrhagic stroke, the main body of evidence is for ischaemic stroke, and data on physical activity and haemorrhagic stroke are lacking in comparison. Profitable topics for further investigation should focus on defining the optimal intensities and durations of exercise required to provide the most substantial reduction in stroke risk for use in both primary and secondary prevention, the frequency of exercise sessions, the effect of gender on risk reduction with exercise, and the duration of observed benefit. For patients with previous stroke, identification and targeting of barriers to exercise delivery could lead to more widespread implementation of exercise prescription in this population. The long-term effect of regular physical activity on recurrent stroke risk in patients with previous stroke merits further study.

\section{References}

[1] Scottish Intercollegiate Guidelines Network (SIGN), Management of Patients with Stroke or TIA: assessment, Investigation, Immediate Management and Secondary Prevention. SIGN 108, A National Clinical Guideline, Edinburgh, UK, 2008.

[2] M. J. O’Donnell, X. Denis, L. Liu et al., "Risk factors for ischaemic and intracerebral haemorrhagic stroke in 22 countries (the INTERSTROKE study): a case-control study," The Lancet, vol. 376, no. 9735, pp. 112-123, 2010.

[3] N. F. Gordon, M. Gulanick, F. Costa et al., "Physical activity and exercise recommendations for stroke survivors: an American Heart Association scientific statement from the Council on Clinical Cardiology, Subcommittee on Exercise, Cardiac Rehabilitation, and Prevention; the Council on Cardiovascular Nursing; the Council on Nutrition, Physical Activity, and Metabolism; and the Stroke Council," Stroke, vol. 35, no. 5, pp. 1230-1240, 2004.

[4] C. M. M. Lawes, D. A. Bennett, V. L. Feigin, and A. Rodgers, "Blood pressure and stroke: an overview of published reviews," Stroke, vol. 35, no. 3, pp. 776-785, 2004.

[5] R. Collins, R. Peto, S. MacMahon et al., "Blood pressure, stroke, and coronary heart disease. Part 2, short-term reductions in blood pressure: overview of randomised drug trials in their epidemiological context," The Lancet, vol. 335, no. 8693, pp. 827-838, 1990.

[6] R. S. Paffenbarger Jr., A. L. Wing, R. T. Hyde, and D. L. Jung, "Physical activity and incidence of hypertension in college alumni," American Journal of Epidemiology, vol. 117, no. 3, pp. 245-257, 1983.

[7] S. N. Blair, N. N. Goodyear, L. W. Gibbons, and K. H. Cooper, "Physical fitness and incidence of hypertension in healthy normotensive men and women," JAMA, vol. 252, no. 4, pp. 487-490, 1984.

[8] L. S. Pescatello, A. E. Fargo, C. N. Leach, and H. H. Scherzer, "Short-term effect of dynamic exercise on arterial blood pressure," Circulation, vol. 83, no. 5, pp. 1557-1561, 1991.

[9] N. Sanossian and B. Ovbiagele, "Multimodality stroke prevention,” Neurologist, vol. 12, no. 1, pp. 14-31, 2006.
[10] E. S. Ford, "Does exercise reduce inflammation? Physical activity and C-reactive protein among U.S. adults," Epidemiology, vol. 13, no. 5, pp. 561-568, 2002.

[11] G. Jennings, L. Nelson, P. Nestel et al., "The effects of changes in physical activity on major cardiovascular risk factors, hemodynamics, sympathetic function, and glucose utilization in man: a controlled study of four levels of activity," Circulation, vol. 73, no. 1, pp. 30-40, 1986.

[12] T. A. Lakka and D. E. Laaksonen, "Physical activity in prevention and treatment of the metabolic syndrome," Applied Physiology, Nutrition and Metabolism, vol. 32, no. 1, pp. 76-88, 2007.

[13] N. M. Moyna and P. D. Thompson, "The effect of physical activity on endothelial function in man," Acta Physiologica Scandinavica, vol. 180, no. 2, pp. 113-123, 2004.

[14] W. Koenig, M. Sund, A. During, and E. Ernst, "Leisuretime physical activity but not work-related physical activity is associated with decreased plasma viscosity: results from a large population sample," Circulation, vol. 95, no. 2, pp. 335-341, 1997.

[15] R. Rauramaa, J. T. Salonen, and K. Seppanen, "Inhibition of platelet aggregability by moderate-intensity physical exercise: a randomized clinical trial in overweight men," Circulation, vol. 74, no. 5, pp. 939-944, 1986.

[16] R. D. Abbott, B. L. Rodriguez, C. M. Burchfiel, and J. D. Curb, "Physical activity in older middle-aged men and reduced risk of stroke: the Honolulu Heart Program," American Journal of Epidemiology, vol. 139, no. 9, pp. 881-893, 1994.

[17] U. Agnarsson, G. Thorgeirsson, H. Sigvaldason, and N. Sigfusson, "Effects of leisure-time physical activity and ventilatory function on risk for stroke in men: the Reykjavik study," Annals of Internal Medicine, vol. 130, no. 12, pp. 987-990, 1999.

[18] H. Ellekjær, J. Holmen, E. Ellekjær, and L. Vatten, "Physical activity and stroke mortality in women: ten-year follow-up of the Nord-Trondelag Health Survey, 1984-1986," Stroke, vol. 31, no. 1, pp. 14-18, 2000.

[19] K. R. Evenson, W. D. Rosamond, J. Cai et al., "Physical activity and ischemic stroke risk: the atherosclerosis risk in communities study," Stroke, vol. 30, no. 7, pp. 1333-1339, 1999.

[20] F. B. Hu, M. J. Stampfer, G. A. Colditz et al., "Physical activity and risk of stroke in women," JAMA, vol. 283, no. 22, pp. 2961-2967, 2000.

[21] D. K. Kiely, P. A. Wolf, L. A. Cupples, A. S. Beiser, and W. B. Kannel, "Physical activity and stroke risk: the Framingham study," American Journal of Epidemiology, vol. 140, no. 7, pp. 608-620, 1994.

[22] R. F. Gillum, M. E. Mussolino, and D. D. Ingram, "Physical activity and stroke incidence in women and men: the NHANES I epidemiologic follow-up study," American Journal of Epidemiology, vol. 143, no. 9, pp. 860-868, 1996.

[23] L. L. Haheim, I. Holme, I. Hjermann, and P. Leren, "Risk factors of stroke incidence and mortality: a 12-year follow-up of the Oslo study," Stroke, vol. 24, no. 10, pp. 1484-1489, 1993.

[24] G. Wannamethee and A. G. Shaper, "Physical activity and stroke in British middle aged men," British Medical Journal, vol. 304, no. 6827, pp. 597-601, 1992.

[25] R. L. Sacco, R. Gan, B. Boden-Albala et al., "Leisure-time physical activity and ischemic stroke risk: the Northern Manhattan Stroke Study," Stroke, vol. 29, no. 2, pp. 380-387, 1998.

[26] R. Shinton and G. Sagar, "Lifelong exercise and stroke," British Medical Journal, vol. 307, no. 6898, pp. 231-234, 1993. 
[27] R. You, J. J. McNeil, H. M. O’Malley, S. M. Davis, and G. A. Donnan, "Risk factors for lacunar infarction syndromes," Neurology, vol. 45, no. 8, pp. 1483-1487, 1995.

[28] R. X. You, J. J. McNeil, H. M. O’Malley, S. M. Davis, A. G. Thrift, and G. A. Donnan, "Risk factors for stroke due to cerebral infarction in young adults," Stroke, vol. 28, no. 10, pp. 1913-1918, 1997.

[29] G. Hu, C. Sarti, P. Jousilahti, K. Silventoinen, N. C. Barengo, and J. Tuomilehto, "Leisure time, occupational, and commuting physical activity and the risk of stroke," Stroke, vol. 36, no. 9, pp. 1994-1999, 2005.

[30] P. T. Williams, "Reduction in incident stroke risk with vigorous physical activity: evidence from 7.7-year follow-up of the national runners' health study," Stroke, vol. 40, no. 5, pp. 1921-1923, 2009.

[31] Physical Activity Guidelines Advisory Committee. Physical Activity Guidelines Advisory Committee Report, US Department of Health and Human Services, Washington, DC, USA, 2008.

[32] I. M. Lee, C. H. Hennekens, K. Berger, J. E. Buring, and J. E. Manson, "Exercise and risk of stroke in male physicians," Stroke, vol. 30, no. 1, pp. 1-6, 1999.

[33] I. M. Lee and R. S. Paffenbarger Jr., "Physical activity and stroke incidence: the Harvard Alumni Health Study," Stroke, vol. 29, no. 10, pp. 2049-2054, 1998.

[34] E. Fossum, G. W. Gleim, S. E. Kjeldsen et al., "The effect of baseline physical activity on cardiovascular outcomes and new-onset diabetes in patients treated for hypertension and left ventricular hypertrophy: the LIFE study," Journal of Internal Medicine, vol. 262, no. 4, pp. 439-448, 2007.

[35] K. D. Lindsted, S. Tonstad, and J. W. Kuzma, "Self-report of physical activity and patterns of mortality in Seventh-Day Adventist men," Journal of Clinical Epidemiology, vol. 44, no. 4-5, pp. 355-364, 1991.

[36] A. Menotti and F. Seccareccia, "Physical activity at work and job responsibility as risk factors for fatal coronary heart disease and other causes of death," Journal of Epidemiology and Community Health, vol. 39, no. 4, pp. 325-329, 1985.

[37] E. M. Simonsick, M. E. Lafferty, C. L. Phillips et al., "Risk due to inactivity in physically capable older adults," American Journal of Public Health, vol. 83, no. 10, pp. 1443-1450, 1993.

[38] A. R. Folsom and M. A. Pereira, "Cardiovascular benefits of endurance exercise," in Endurance in Sports, R. J. Shephard and P.-O. Astrand, Eds., vol. 2 of The Encyclopedia of Sports Medicine, pp. 688-707, Blackwell Science, Oxford, UK, 2000.

[39] C. D. Lee, A. R. Folsom, and S. N. Blair, "Physical activity and stroke risk: a meta-analysis," Stroke, vol. 34, no. 10, pp. 24752481, 2003.

[40] G. C. W. Wendel-Vos, A. J. Schuit, E. J. M. Feskens et al., "Physical activity and stroke. A meta-analysis of observational data," International Journal of Epidemiology, vol. 33, no. 4, pp. 787798, 2004.

[41] C. D. Reimers, G. Knapp, and A. K. Reimers, "Exercise as stroke prophylaxis," Deutsches Arzteblatt, vol. 106, no. 44, pp. 715-721, 2009.

[42] A. Galimanis, M. L. Mono, M. Arnold, K. Nedeltchev, and H. P. Mattle, "Lifestyle and stroke risk: a review," Current Opinion in Neurology, vol. 22, no. 1, pp. 60-68, 2009.

[43] T. Kurth, S. C. Moore, J. M. Gaziano et al., "Healthy lifestyle and the risk of stroke in women," Archives of Internal Medicine, vol. 166, no. 13, pp. 1403-1409, 2006.

[44] J. R. Sattelmair, T. Kurth, J. E. Buring, and I. M. Lee, "Physical activity and risk of stroke in women," Stroke, vol. 41, no. 6, pp. 1243-1250, 2010.
[45] H. Noda, H. Iso, H. Toyoshima et al., "Walking and sports participation and mortality from coronary heart disease and stroke," Journal of the American College of Cardiology, vol. 46, no. 9, pp. 1761-1767, 2005.

[46] J. Z. Willey, Y. P. Moon, M. C. Paik, B. Boden-Albala, R. L. Sacco, and M. S. V. Elkind, "Physical activity and risk of ischemic stroke in the Northern Manhattan study," Neurology, vol. 73, no. 21, pp. 1774-1779, 2009.

[47] J. E. Manson, P. Greenland, A. Z. LaCroix et al., "Walking compared with vigorous exercise for the prevention of cardiovascular events in women," The New England Journal of Medicine, vol. 347, no. 10, pp. 716-725, 2002.

[48] S. P. Whelton, A. Chin, X. Xin, and J. He, "Effect of aerobic exercise on blood pressure: a meta-analysis of randomized, controlled trials," Annals of Internal Medicine, vol. 136, no. 7, pp. 493-503, 2002.

[49] A. J. Grau, C. Barth, B. Geletneky et al., "Association between recent sports activity, sports activity in young adulthood, and stroke," Stroke, vol. 40, no. 2, pp. 426-431, 2009.

[50] T. Thom, N. Haase, W. Rosamond et al., "Heart disease and stroke statistics-2006 Update: a report from the American Heart Association Statistics Committee and Stroke Statistics Subcommittee," Circulation, vol. 113, no. 6, pp. e85-e151, 2006.

[51] V. J. Mol and C. A. Baker, "Activity intolerance in the geriatric stroke patient," Rehabilitation Nursing, vol. 16, no. 6, pp. 337343, 1991.

[52] J. H. Rimmer, A. E. Rauworth, E. C. Wang, T. L. Nicola, and B. Hill, "A preliminary study to examine the effects of aerobic and therapeutic (Nonaerobic) exercise on cardiorespiratory fitness and coronary risk reduction in stroke survivors," Archives of Physical Medicine and Rehabilitation, vol. 90, no. 3, pp. 407412, 2009.

[53] P. Langhorne, F. Coupar, and A. Pollock, "Motor recovery after stroke: a systematic review," The Lancet Neurology, vol. 8, no. 8, pp. 741-754, 2009.

[54] Atlantis, ECASS, and NINDs rt-PA Study Group Investigator, "Association of outcome with early stroke treatment: pooled analysis of ATLANTIS, ECASS, and NINDS rt-PA stroke trials," The Lancet, vol. 363, pp. 768-774, 2004.

[55] T. J. Quinn, S. Paolucci, K. S. Sunnerhagen et al., "Evidencebased stroke rehabilitation: an expanded guidance document from the European Stroke Organisation (ESO) guidelines for management of ischaemic stroke and transient ischaemic attack 2008," Journal of Rehabilitation Medicine, vol. 41, no. 2, pp. 99-111, 2009.

[56] D. H. Saunders, C. A. Greig, A. Young, and G. E. Mead, "Physical fitness training for stroke patients," Cochrane Database of Systematic Reviews, no. 1, Article ID CD003316, 2004.

[57] D. Rand, J. J. Eng, P. F. Tang, J. S. Jeng, and C. Hung, "How active are people with stroke?: use of accelerometers to assess physical activity," Stroke, vol. 40, no. 1, pp. 163-168, 2009.

[58] G. Mead, "Exercise after stroke," BMJ, vol. 339, Article ID b2795, 2009.

[59] D. S. Saunders, Physical fitness training after stroke: a systematic review and meta-analysis. Third UK stroke forum. Book of abstracts p15, 2008, http://www.ukstrokeforum.org/events/ past_forum_conferences/2008_uksf_conference.html.

[60] G. Robinson-Smith, M. V. Johnston, and J. Allen, "Selfcare self-efficacy, quality of life, and depression after stroke," Archives of Physical Medicine and Rehabilitation, vol. 81, no. 4, pp. 460-464, 2000. 
[61] J. R. Brinkmann and T. A. Hoskins, "Physical conditioning and altered self-concept in rehabilitated hemiplegic patients," Physical Therapy, vol. 59, no. 7, pp. 859-865, 1979.

[62] R. F. Macko, G. V. Smith, C. L. Dobrovolny, J. D. Sorkin, A. P. Goldberg, and K. H. Silver, "Treadmill training improves fitness reserve in chronic stroke patients," Archives of Physical Medicine and Rehabilitation, vol. 82, no. 7, pp. 879-884, 2001.

[63] K. Potempa, M. Lopez, L. T. Braun, J. P. Szidon, L. Fogg, and T. Tincknell, "Physiological outcomes of aerobic exercise training in hemiparetic stroke patients," Stroke, vol. 26, no. 1, pp. 101-105, 1995.

[64] J. H. Rimmer, B. Riley, T. Creviston, and T. Nicola, "Exercise training in a predominantly African-American group of stroke survivors," Medicine and Science in Sports and Exercise, vol. 32, no. 12, pp. 1990-1996, 2000.

[65] B. J. Fletcher, S. B. Dunbar, J. M. Felner et al., "Exercise testing and training in physically disabled men with clinical evidence of coronary artery disease," American Journal of Cardiology, vol. 73, no. 2, pp. 170-174, 1994.

[66] P. D. Thompson, D. Buchner, I. L. Piña et al., "Exercise and physical activity in the prevention and treatment of atherosclerotic cardiovascular disease: a statement from the council on clinical cardiology (subcommittee on exercise, rehabilitation, and prevention) and the council on nutrition, physical activity, and metabolism (subcommittee on physical activity)," Circulation, vol. 107, no. 24, pp. 3109-3116, 2003.

[67] C. D. Lee and S. N. Blair, "Cardiorespiratory fitness and stroke mortality in men," Medicine and Science in Sports and Exercise, vol. 34, no. 4, pp. 592-595, 2002.

[68] R. R. Pate, M. Pratt, S. N. Blair et al., "Physical activity and public health: a recommendation from the Centers for Disease Control and Prevention and the American College of Sports Medicine," JAMA, vol. 273, no. 5, pp. 402-407, 1995.

[69] M. Y. C. Pang, J. J. Eng, A. S. Dawson, and S. Gylfadóttir, "The use of aerobic exercise training in improving aerobic capacity in individuals with stroke: a meta-analysis," Clinical Rehabilitation, vol. 20, no. 2, pp. 97-111, 2006.

[70] E. J. Roth, M. Mueller, and D. Green, "Cardiovascular response to physical therapy in stroke rehabilitation," Neurological Rehabilitation, vol. 2, pp. 7-13, 1992.

[71] M. J. MacKay-Lyons and L. Makrides, "Cardiovascular stress during a contemporary stroke rehabilitation program: is the intensity adequate to induce a training effect?" Archives of Physical Medicine and Rehabilitation, vol. 83, no. 10, pp. 1378$1383,2002$.

[72] S. J. Olney, M. P. Griffin, T. N. Monga, and I. D. McBride, "Work and power in gait of stroke patients," Archives of Physical Medicine and Rehabilitation, vol. 72, no. 5, pp. 309-314, 1991.

[73] R. W. Bohannon and S. Walsh, "Nature, reliability, and predictive value of muscle performance measures in patients with hemiparesis following stroke," Archives of Physical Medicine and Rehabilitation, vol. 73, no. 8, pp. 721-725, 1992.

[74] E. Hamrin, G. Eklund, and A. K. Hillgren, "Muscle strength and balance in post-stroke patients," Upsala Journal of Medical Sciences, vol. 87, no. 1, pp. 11-26, 1982.

[75] S. A. Sharp and B. J. Brouwer, "Isokinetic strength training of the hemiparetic knee: effects on function and spasticity," Archives of Physical Medicine and Rehabilitation, vol. 78, no. 11, pp. 1231-1236, 1997.

[76] A. Weiss, T. Suzuki, J. Bean, and R. A. Fielding, "High intensity strength training improves strength and functional performance after stroke," American Journal of Physical Medicine and Rehabilitation, vol. 79, no. 4, pp. 369-376, 2000.
[77] J. Bernhardt, H. Dewey, A. Thrift, and G. Donnan, "Inactive and alone: physical activity within the first 14 days of acute stroke unit care," Stroke, vol. 35, no. 4, pp. 1005-1009, 2004.

[78] S. L. Wolf, C. J. Winstein, J. P. Miller et al., "Effect of constraint-induced movement therapy on upper extremity function 3 to 9 months after stroke: the EXCITE randomized clinical trial," JAMA, vol. 296, no. 17, pp. 2095-2104, 2006.

[79] O. Armagan, F. Tascioglu, and C. Oner, "Electromyographic biofeedback in the treatment of the hemiplegic hand: a placebo-controlled study," American Journal of Physical Medicine and Rehabilitation, vol. 82, no. 11, pp. 856-861, 2003.

[80] J. V. Basmajian, C. A. Gowland, and A. J. Finlayson, "Stroke treatment: comparison of integrated behavioral physical therapy vs traditional physical therapy programs," Archives of Physical Medicine and Rehabilitation, vol. 68, no. 5, pp. 267272, 1987.

[81] S. J. Page, P. Levine, and A. C. Leonard, "Effects of mental practice on affected limb use and function in chronic stroke," Archives of Physical Medicine and Rehabilitation, vol. 86, no. 3, pp. 399-402, 2005.

[82] S. J. Page, P. Levine, and A. Leonard, "Mental practice in chronic stroke: results of a randomized, placebo-controlled trial," Stroke, vol. 38, no. 4, pp. 1293-1297, 2007.

[83] F. Amirabdollahian, R. Loureiro, E. Gradwell, C. Collin, W. Harwin, and G. Johnson, "Multivariate analysis of the Fugl-Meyer outcome measures assessing the effectiveness of GENTLE/S robot-mediated stroke therapy," Journal of NeuroEngineering and Rehabilitation, vol. 4, article 4, 2007.

[84] B. T. Volpe, D. Lynch, A. Rykman-Berland et al., "Intensive sensorimotor arm training mediated by therapist or robot improves hemiparesis in patients with chronic stroke," Neurorehabilitation and Neural Repair, vol. 22, no. 3, pp. 305-310, 2008.

[85] S. Masiero, A. Celia, G. Rosati, and M. Armani, "Roboticassisted rehabilitation of the upper limb after acute stroke," Archives of Physical Medicine and Rehabilitation, vol. 88, no. 2, pp. 142-149, 2007.

[86] K. C. Stewart, J. H. Cauraugh, and J. J. Summers, "Bilateral movement training and stroke rehabilitation: a systematic review and meta-analysis," Journal of the Neurological Sciences, vol. 244, no. 1-2, pp. 89-95, 2006.

[87] H. S. Jorgensen, H. Nakayama, H. O. Raaschou, and T. S. Olsen, "Recovery of walking function in stroke patients: the Copenhagen stroke study," Archives of Physical Medicine and Rehabilitation, vol. 76, no. 1, pp. 27-32, 1995.

[88] I. Van de Port, Predicting Outcomes in Patients with Chronic Stroke: Findings of a 3 Year Follow Up Study, chapter 5: effects of exercise training programs on walking competency after stroke: a systematic review, 2006.

[89] J. Mehrholz, C. Werner, J. Kugler, and M. Pohl, "Electromechanical-assisted training for walking after stroke," Cochrane Database of Systematic Reviews, no. 4, Article ID CD006185, 2007.

[90] A. M. Moseley, A. Stark, I. D. Cameron, and A. Pollock, "Treadmill training and body weight support for walking after stroke," Cochrane Database of Systematic Reviews, no. 4, Article ID CD002840, 2005.

[91] M. Y. Lee, M. K. Wong, and F. T. Tang, "Using biofeedback for standing-steadiness, weight-bearing training," IEEE Engineering in Medicine and Biology Magazine, vol. 15, no. 6, pp. 112-116, 1996.

[92] C. M. Sackley and N. B. Lincoln, "Single blind randomized controlled trial of visual feedback after stroke: effects on stance 
symmetry and function," Disability and Rehabilitation, vol. 19, no. 12 , pp. 536-546, 1997.

[93] A. Shumway-Cook, D. Anson, and S. Haller, "Postural sway biofeedback: its effect on reestablishing stance stability in hemiplegic patients," Archives of Physical Medicine and Rehabilitation, vol. 69, no. 6, pp. 395-400, 1988.

[94] A. M. K. Wong, M. Y. Lee, J. K. Kuo, and F. T. Tang, "The development and clinical evaluation of a standing biofeedback trainer," Journal of Rehabilitation Research and Development, vol. 34, no. 3, pp. 322-327, 1997.

[95] R. McClellan and L. Ada, "A six-week, resource-efficient mobility program after discharge from rehabilitation improves standing in people affected by stroke: placebo-controlled, randomised trial," Australian Journal of Physiotherapy, vol. 50, no. 3, pp. 163-167, 2004.

[96] N. M. Salbach, N. E. Mayo, S. Wood-Dauphinee, J. A. Hanley, C. L. Richards, and R. Côté, "A task-orientated intervention enhances walking distance and speed in the first year post stroke: a randomized controlled trial," Clinical Rehabilitation, vol. 18 , no. 5, pp. 509-519, 2004.

[97] W. De Weerdt, G. Nuyens, H. Feys et al., "Group physiotherapy improves time use by patients with stroke in rehabilitation," Australian Journal of Physiotherapy, vol. 47, no. 1, pp. 53-61, 2001.

[98] G. Kwakkel, R. Van Peppen, R. C. Wagenaar et al., "Effects of augmented exercise therapy time after stroke: a meta-analysis," Stroke, vol. 35, no. 11, pp. 2529-2536, 2004. 


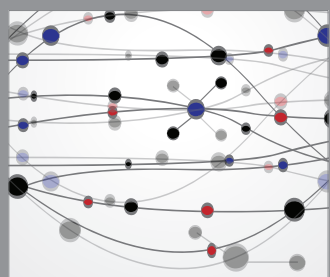

The Scientific World Journal
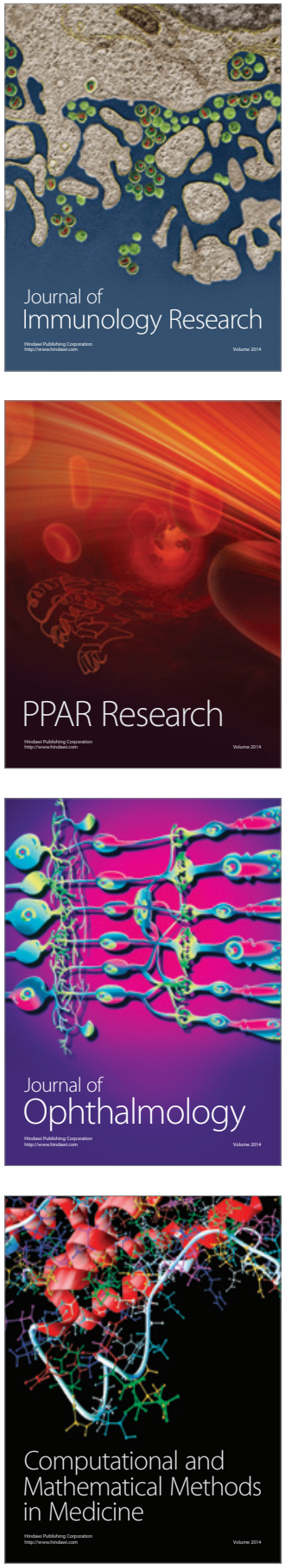

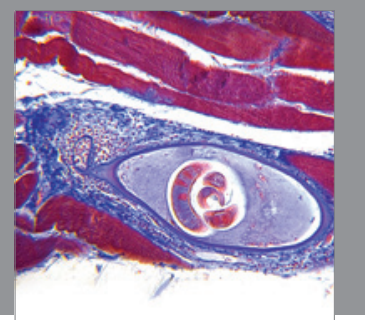

Gastroenterology

Research and Practice
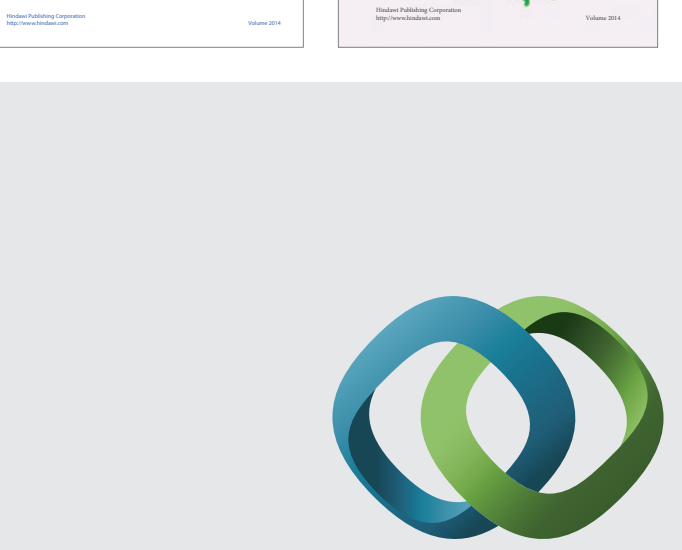

\section{Hindawi}

Submit your manuscripts at

http://www.hindawi.com
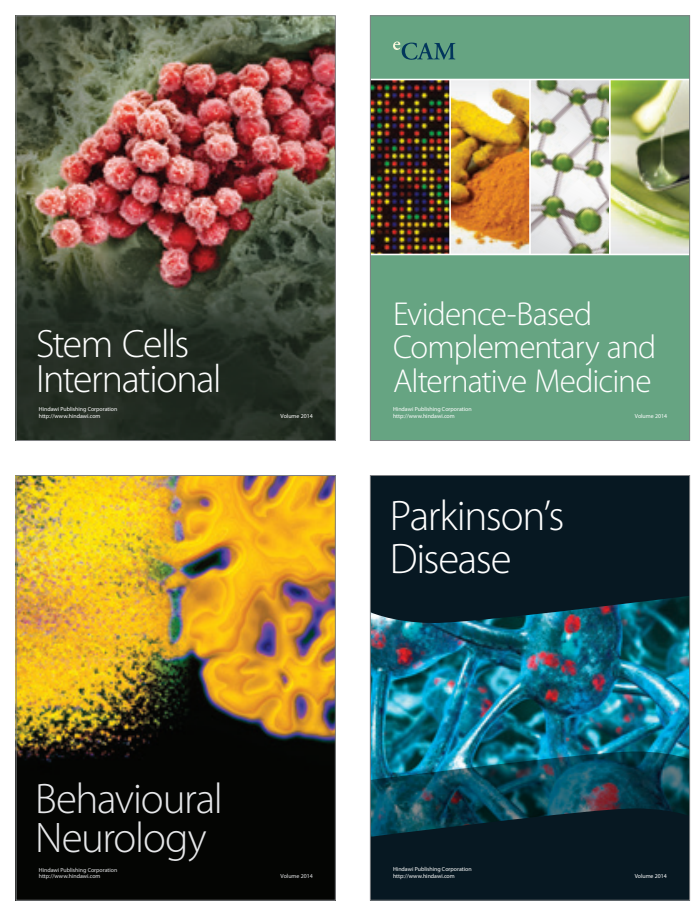

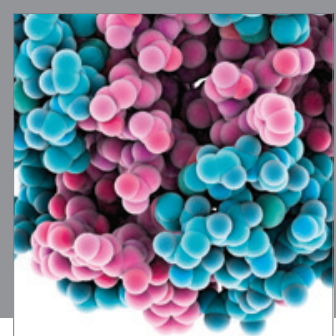

Journal of
Diabetes Research

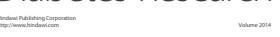

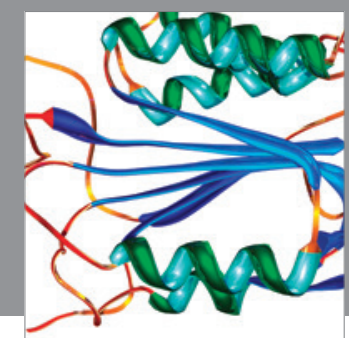

Disease Markers
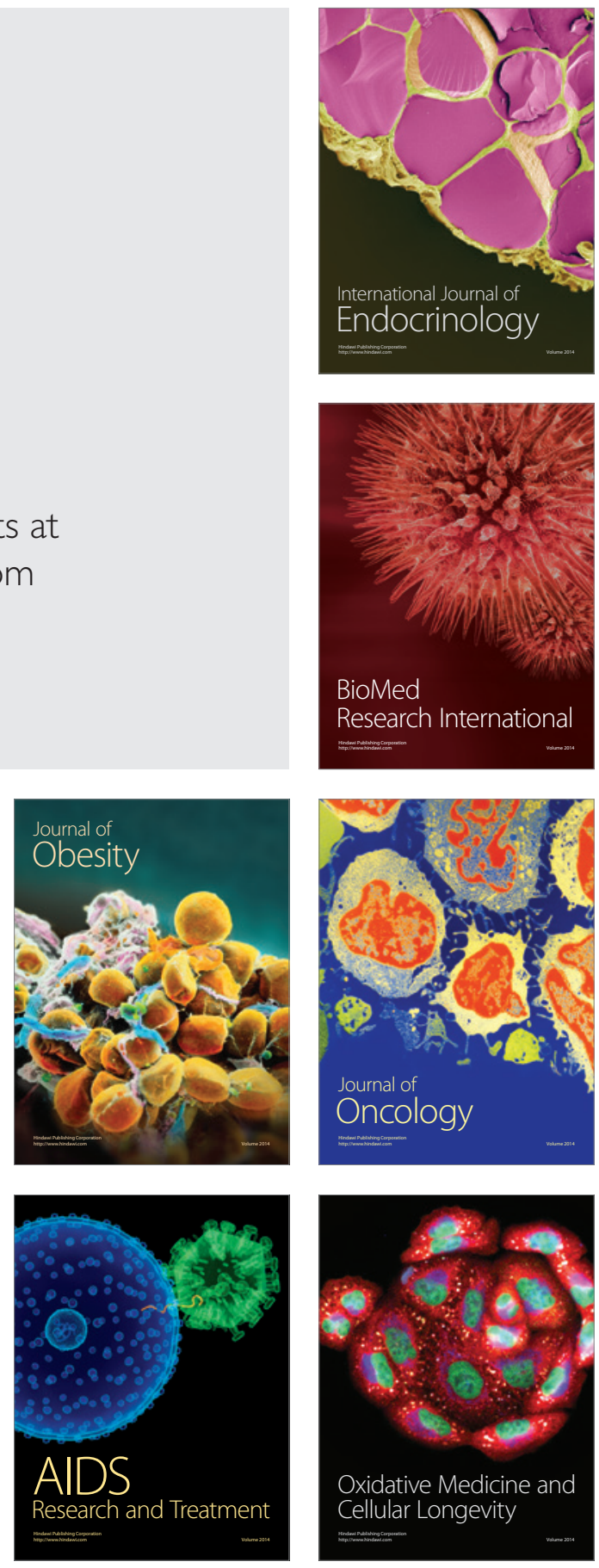